\title{
Total Polyphenols Content and Antioxidant Activity of Different Tea Commercially Produced in Nepal
}

\author{
ROJEENA SHRESTHA ${ }^{1^{*}}$, JIWAN PRAVA LAMA ${ }^{2}$ and KSHITIJ SHRESTHA ${ }^{2}$
}

\author{
${ }^{1}$ Lalitpur Valley College, Jawalakhel, Lalitpur, Nepal \\ ${ }^{2}$ Department of Food Technology and Quality Control, Babarmahal, Kathmandu, Nepal
}

This study was conducted to assess and compare the total polyphenol content (TPC), antioxidant activity of different tea varieties commercially produced in Nepal. Nine different brands of tea samples, three from each CTC, orthodox and green tea were collected from different parts of Kathmandu valley. TPC was analyzed as per folin-ciocalteu method and antioxidant activity as per DPPH (2, 2-diphenyl-1-picrylhrdrazine) free radical scavenging capacity. The TPC was found to be 4.60, 8.79, $18.20 \mathrm{mg}$ of phenol equivalent (PE)/gm of sample in CTC, orthodox and green tea respectively. Green tea Emerald and green tea Kanchanjunga contained the highest level of polyphenol. Antioxidant activity (for 0.36 mg of tea sample) was found to be 25.04, 43.86, and 72.39\% for CTC, orthodox and green tea respectively. Moreover, some commercial brands of green tea (Emerald and Kanchanjunga) showed the highest antioxidant activity. The TPC and antioxidant activity of different commercial brands of tea were found to be positively correlated $(r=0.97)$.

Keywords: Total polyphenol content, Antioxidant activity, Green tea, Black tea, Catechins

\section{Introduction}

Tea is one of the most commonly consumed beverages, with an annual consumption of $0.36 \mathrm{~kg}$ per person in Nepal (Anon, 2009). It is an evergreen shrub with heavily branched. Depending on the manufacturing process, tea can be classified into three types namely green, black and Oolong (Yang et al., 2001). Green tea is manufactured by steaming or panning the tea leaves so as to inactivate enzymes, mainly polyphenol oxidase. Besides, the color of green tea is also maintained (Banarjee, 2005). In the manufacture of black tea, the tea leaves are subjected to withering, rolling, fermentation, drying and packaging. The withering process reduces the water content slightly and rolling helps to open cells leading to the release of enzymes and juices. The fermentation process allows oxidation of various polyphenols present in the juices by the enzyme polyphenol oxidase. Hence the color of tea is changed to reddish copper from green. Oolong tea is subjected to light withering, followed by light fermentation (Manay and Shadaksharaswamy, 2001).

Plant polyphenols are aromatic hydroxylated compounds which are among the most potent and therapeutically useful bioactive compounds. The polyphenol consumption may play a significant role in reducing the incidence of degenerative diseases (Kinsella et al., 1993). Plant polyphenols possess antioxidant, anti-carcinogenic and anti-artioscleriotic properties (Dufresne and Farnworth, 2001; Wang and Helliwell, 2001; Filip and Ferraro, 2003; Atoui et al., 2005). They act as reducing agents, hydrogen donators, singlet oxygen quenchers and metal chelators (Rice-Evans et al., 1997).

In case of tea leaves these are the main compounds which are responsible for the unique characteristic of processed teas. Tea contains $36 \%$ polyphenols on average (Shahidi,

*Correspondingauthor,E-mail: rojeenashrestha@gmail.com
2000).The major polyphenolic constituents of fresh tea shoot are given in Table 1.

Table 1. Major polyphenolic constituents of fresh tea shoot

\begin{tabular}{lcr}
\hline \multicolumn{1}{c}{ Compounds \% } & $\begin{array}{c}\text { Dry } \\
\text { weight \% }\end{array}$ & Contribution \\
\hline Total polyphenols & $25-30$ & Astringency \\
Flavonols & & \\
(-) Epigallocatechin gallate & $8-12$ & \\
(-)Epicatechin gallate & $3-6$ & \\
(-) Epigallo catechin & $3-6$ & \\
(-) Epicatechin & $1-3$ & \\
(+) Catechin & $1-2$ & \\
(+) Gallocatechin & $3-4$ & \\
Flavonols and flavonolglycosides & $3-4$ & \\
Leuco anthocyanins & $2-3$ & \\
Polyphenolic acids and depsides & $3-4$ & \\
\hline Source: Tea Research Association (2003)
\end{tabular}

The major polyphenoloic compounds in tea are catechins, epicatechins, gallocatechins, epigallocatechins, epicatechin gallate, epigallocatechin gallate, theaflavins, thearubigins etc. (Quan et al., 2007). Figure 2 and 3 shows the major tea polyphenols. The polyphenolic composition of tea undergoes change with leaf age and its activity is at its optimum in young leaves (Banarjee, 2005). The polyphenol content is influenced by many factors such as tea types, commercial brands of tea, origin, tea plantation area and infusion conditions etc. (Suteerapataron et al., 2008).

Young tea shoots have a high content of polyphenols and as much as $30 \%$ of that consists of catechins (flavon-3-ols) (Varnam and Sutherland, 1994). Hence catechins are the major polyphenols that are present in high concentration mainly in the young tea shoots (Forrest and Bendall, 1969). Other phenolic are present at low concentrations and does not play significant part in the formation of the characteristics 
polyphenols of black and green tea. Change in the polyphenolic compounds during the fermentation of tea: The changes in the polyphenolic compounds during the fermentation of tea have been shown in Figure 1.

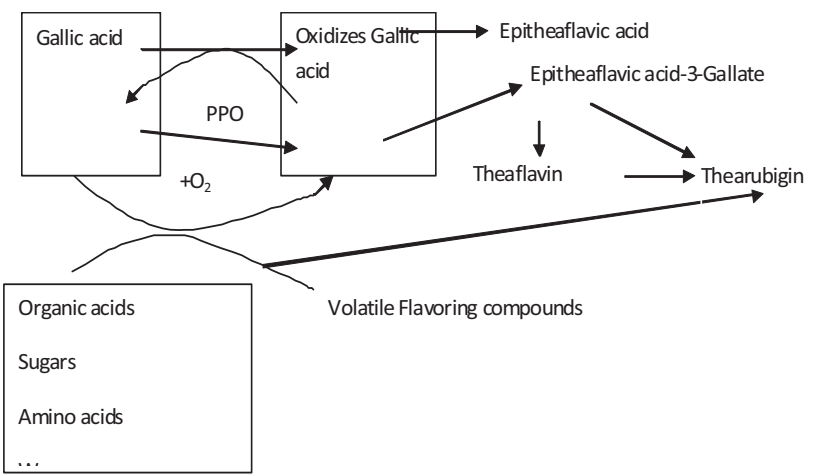

Figure 1. Summary of reactions during fermentation and drying (from Jain, 1999)

During tea fermentation, the primary reaction involves the oxidative transformation of four different kinds of flavonolsepicatechin, epicatechin-3-gallate, epigallocatechin, epigallocatechin-3-gallate to respective 3', 4'-orthoquinones by polyphenol oxidase (PPO). The oxidized tea flavonols produces epitheaflavic acid, theaflavins and thearubigins on condensation (Jain, 1999). Theaflavins determine the cup quality and brightness of black tea. In the tea liquor, thearubigins consist about $30-60 \%$ of the solid. Thearubigins impart color, strength and briskness of the brewed tea (Banarjee, 2005).

An antioxidant can be defined as "any substances that when present at low concentration compared to that of an oxidizable substrate significantly delays or inhibits the oxidation of that substrate" (Percival, 1998; Young and Woodside, 2001). Plant polyphenols possess antioxidant, anti-carcinogenic and antiartioscleriotic properties (Dufresne and Farnworth, 2001; Wang and Helliwell, 2001; Filip and Ferraro, 2003; A toui et al., 2005). They act as reducing agents, hydrogen donators, singlet oxygen quenchers and metal chelators (Rice-Evans et al., 1997).

Role of antioxidant in human body: Free radicals are unsuitable molecules including reactive oxygen species. The common reactive species include superoxide $\left(\mathrm{O}_{2}\right)$ anion, hydrogen peroxide $\left(\mathrm{H}_{2} \mathrm{O}_{2}\right)$, peroxyl (ROO) radicals, and reactive hydroxyl $(\mathrm{OH})$ radicals. The nitrogen derived free radicals are nitric oxide (NO), and peroxy nitrite anion (ONOO) (Joyce, 1987). During normal cellular processes these naturally occur in the body as a result of chemical reactions. They can also be formed in response to excess pollution, too much UV sunlight and exposure to cigarette smoke. Besides chemicals toxins, deep fried and spicy food, physical stress also may form free radicals (Suteerapataranon et al., 2008).
Relation between polyphenols and antioxidant activity of tea: Many antioxidants isolated from higher plants are polyphenols. These polyphenols have been reported to exhibit biological activity as antibacterial, anti-carcinogenic, anti-inflammatory, anti-viral, anti-allergic, estrogenic, and immune-stimulating effects (Larson, 1988). Phenolics possess antioxidant activity due to their Redox properties which allow them to act as reducing agents, hydrogen donors, and metal chelating potential (Parr and Bowell, 2000). Comparing with the other natural antioxidant such as vitamins C, F and Scarotene, tea polyphenols are reported to possess stronger antioxidant activity in vitro lipoprotein oxidation model (Vinson and Dabbagh, 1998). According to Pan et al., (2003), tea polyphenols have been found to possess stronger antioxidant activity than the artificial antioxidants such as butylated hydroxyl toluene, butylated hydroxyl anisole, DLtocopherol. Besides tea polyphenols are also less toxic as compared to the above mentioned artificial antioxidant. It has been found from the research that the antioxidant activity decreased in the order of semi-fermentive tea $>$ non-fermentive tea $>$ fermented tea (Yen and Chen, 1995). The major flavonoids possessing antioxidant activity are catechins in the order of $\mathrm{EGCG}>\mathrm{EGC}>\mathrm{ECG}>\mathrm{EC}$ (Matsuzaki and Hara, 1985).

Research based on DPPH (2, 2-diphenyl-1-picrylhydrazyl) free radical scavenging assay have shown that the TPC were found well correlated with the antioxidant activity $(\mathrm{r}=0.8141)$ (Anesini et al., 2008). Quan et al., (2007) also reported very good correlation between TPC and antioxidant activity $\left(\mathrm{EC}_{50}-\right.$ the lowest concentration needed to scavenge $50 \%$ of initial DPPH), $r=0.81$. Hajimahmoodi et al., (2008) also claimed good correlation between total TPC and antioxidant activity by the ferric reducing antioxidant power assay. Tea polyphenols have been found to possess the stronger antioxidant activity, mainly catechin (Dufresne and Farnworth, 2001). Rice-Evans et al., (1997) stated that the oxidized products of catechins have lower antioxidant activity than those of catechins. However the conversion of catechins to theaflavins during the tea fermentation doesn't have been reported to affect significantly its free radical scavenging capacity. The catechins in the green tea and theaflavins in black tea are reported to possess equal antioxidant activity (Leung et al., 2001). Lee et al., (2002) also found that green tea has stronger antioxidant activity than black tea. Yakozawa et al., (1998) also affirmed that green tea extracts showed higher radical scavenging efficiency than black tea extract (antioxidant activity based on DPPH radical scavenging capacity).

\section{Materials and Methods}

Materials: DPPH (2, 2-diphenyl-1-picrylhrdrazine) and Folin -Ciocalteu reagents were purchased from Sigma Chemical Co. (Germany).

Sample collection: Nine different commercial brands of prepackaged tea samples including CTC, green and orthodox; including three of each type of tea were taken for analysis. The samples were collected from the different parts of 
<smiles>Oc1ccc([C@H]2[CH][C@@H](O)CC3C(=CC(O)CC3O)O2)cc1O</smiles>

Figure 2.a. (+) Catechin<smiles>OC1CC(O)C2CC(O)C(C3CC(O)C(O)C(O)C3)OC2C1</smiles>

Figure 2.b. (-) Gallocatechin<smiles>O=C(OC1Cc2c(O)cc(O)cc2OC1C1CCC(O)C(O)C1)C1CC(O)C(O)C(O)C1</smiles>

Figure 2.d. (-) Epigallocatechin<smiles>O=C(O[C@H]1Cc2c(O)cc(O)cc2O[C@H]1c1cc(O)c(O)c(O)c1)c1cc(O)c(O)c(O)c1</smiles>

Fig. 2.g. (-)Gallocatechin gallate
Figure 2.e. (-) Catechin gallate<smiles>OC1CCC([C@H]2C[C@@H](O)CC3C(O)CC(O)CC3O2)CC1</smiles>

Figurer 2.c. (-) Epicatechin

Figure 2. Major green tea polyphenols (Dalluge and Nelson, 2000)<smiles>O=c1c(O)cc([C@H]2Oc3cc(O)cc(O)c3C[C@H]2O)cc2c([C@@H]3Oc4cc(O)cc(O)c4C[C@H]3O)cc(O)c(O)c12</smiles>

Fig. 3.a. Theaflavins

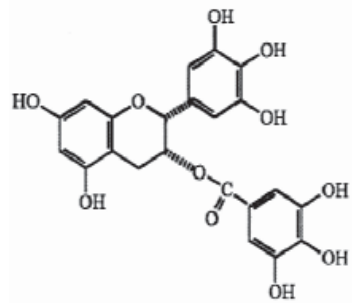

Fig. 2.h. (-)Epigallocatechin gallate

Figure 3. Chemical structures of major black tea polyphenols (from Dalluge and Nelson, 2000)

Kathmandu valley, based on purposive sampling. CTC tea included Tokla tea, Mechi tea and Welcome tea. Orthodox tea included Dhankute tea, Antuvalley tea and Kanchanjunga tea, whereas green tea included Kanchanjunga green tea, Sencha tea and Emerald tea. Here the tea "type" refers to CTC, orthodox and green tea and "commercial brand" refers to altogether nine different tea samples taken for the analysis.<smiles>O=C(O)CC[C@H](c1cc([C@@H]2Oc3cc(O)cc(O)c3C[C@H]2O)cc(O)c(=O)c1C(=O)O)[C@H]1Cc2cc(O)cc(O)c2C[C@H]1O</smiles>

Fig. 3.b. Thearubigin

\section{Determination of total phenolics content and antioxidant} activity

Reagents required: Distilled water, methanol (HPLC grade), ethyl acetate (HPLC grade) and sodium sulfate.

Preparation of tea infusion: Clean and dry conical flask (1200 $\mathrm{ml}$ ) was taken and fifteen grams of tea were weighed and then infused into $1200 \mathrm{ml}$ of boiling water for 3 minutes. The 
infusion was brought to room temperature and then filtered through Whatmann No.4 paper and then concentrated under vacuum (reduced pressure and temperature, $60^{\circ} \mathrm{C}$ ) to a final volume of $50 \mathrm{ml}$. From the concentrated sample polyphenols were extracted twice using ethyl acetate $(100 \mathrm{ml} \times 2)$. The extracts were combined and the dried over sodium sulfate, then concentrated under vacuum to dryness. The residue obtained was re-dissolved in $5 \mathrm{ml}$ of methanol for further analysis.

Determination of the total phenolics content in the extracts Principle: In the folin-ciocalteu method, the extracted sample is diluted to suitable concentration and the diluted sample when treated with the reagent folin-ciocalteu, produces blue molybdenum-tungsten complex. The complex is formed by the oxidation of phenolics compounds in the sample with folin-ciocalteu. Thus produced color is measured in spectrophotometer at $725 \mathrm{~nm}$.

Reagents required: Sodium carbonate, distilled water, methanol (HPLC grade) and folin ciocalteu's reagent (Sigma Company).

Procedure: The Folin-Ciocalteu method (Zheng and Wang, 2001) was used for the determination of total phenolics content. A calibration curve of phenol was prepared and the results were expressed as $\mathrm{mg}$ phenol $/ 100 \mathrm{ml}$. In this method 5 $\mathrm{ml}$ of distilled water was added to a $10 \mathrm{ml}$ volumetric flask. The suitable volume of herb extract was transferred into the volumetric flask to obtain the absorbance in the range of the prepared calibration curve. About $0.2 \mathrm{ml}$ of folin-ciolcalteu reagent was added and shaken well for proper mixing. After 3 minutes, $0.4 \mathrm{ml}$ of saturated sodium carbonate solution was added, mixed well and the volume were made up with the distilled water. The flask was kept in dark for 1 hour for the steady state and the absorbance was measured at $725 \mathrm{~nm}$ using UV-Spectrophotometer.

\section{Determination of the antioxidant activity of the extracts}

DPPH (2, 2-diphenyl-1-picrylhydrazyl), due to its delocalization of spare electron throughout the molecule, is a suitable free radical. This delocalization gives deep violet color when DPPH is dissolved in methanol, with an absorption maximum at $515 \mathrm{~nm}$. As the extracted tea sample exhibit antioxidant capacity, such sample at suitable concentration when mixed with DPPH, donate a hydrogen atom to free radical scavenger-DPPH. Then the DPPH molecule is reduced and the original violet color is lost, depending upon the capacity of the sample to reduce the DPPH. However, a residual pale color may remain due to picryl group present on DPPH molecule.

Reagents required: Distilled water, methanol (HPLC) grade and DPPH (2, 2-diphenyl-1-picrylhydrazyl) $-6 \times 10^{-5} \mathrm{M}$ in methanol from sigma company.

Procedure: DPPH radical method was used for the determination of antioxidant activity of the tea extracts. In this process a methanolic solution of the tea extract of suitable concentration $(300 \mu \mathrm{l}$, containing $0.36 \mathrm{mg}$ of methanol) was added to the $1.94 \mathrm{ml}$ of DPPH solution $\left(6 \times 10^{-5} \mathrm{M}\right)$ in methanol. The decrease in absorbance was measured at $515 \mathrm{~nm}$ using UV spectrophotometer until the reaction reached the steady state in the dark (half an hour) (Siddhuraju and Becker, 2003).

Calculation: The antioxidant activity was calculated using the following equation:

$\%$ Antioxidant activity $=\left[\left(\right.\right.$ Absorbance $_{\mathrm{C}}-$ Absorbance $\left._{\mathrm{E}}\right) /$

Where, Absorbance $\left.{ }_{\mathrm{C}}\right] \times 100$

Absorbance $_{\mathrm{C}}=$ Absorbance of control Absorbance $_{\mathrm{E}=}$ Absorbance of extract

Statistical analysis: Results were expressed as mean \pm SD obtained from triplicate observations. Graphs with error bar (95\% confidence interval) were made using Microsoft Excel 2007. One way ANOVA (analysis of variance) was carried out for data on TPC and antioxidant activity and average were compared among different types and commercial brands of tea using post hoc multiple comparison Tukey test. Correlation coefficients were calculated between TPC and antioxidant activity. All the statistical analyses were performed at 5\% level of significance using the software Splus 8.0 for windows (Insight-full Corp., Seatle, WA, USA).

\section{Results and Discussion}

Nine different commercial brands of tea samples including CTC, Orthodox and Green tea (consisting three of each type) were collected from the different parts of Kathmandu valley for the research. Tea has been reported to have higher polyphenol content and possess antioxidant activity. Hence the polyphenol content and antioxidant activity in Nepalese tea were studied in order to compare among different tea types and commercial brands of tea. Besides, the possible correlation between TPC and antioxidant activity was also studied.

Total polyphenol content of different tea types and commercial brands of tea: The polyphenol content of different tea types and commercial brands of tea are shown in Table 2 and 3 respectively. Tea contains $36 \%$ polyphenols on average (Shahidi, 2000). Tea Research Association (2003) has mentioned total polyphenols from 25 to $30 \%$ (dry weight) in a fresh tea shoot. At $5 \%$ level of significance, the average total polyphenol content of the different tea commercial brands of tea were reported to be lower as compared to the research data mentioned in Table 2.

The mean TPC of the different commercial brands of tea were significantly different $(\mathrm{p}<0.05)$. Among the commercial brands of tea, the highest TPC was reported in green tea Emerald, which wasn't significantly different from green tea Kanchanjunga, but it was significantly higher from all other remaining tea commercial brands of tea (Table 3 ). 
Table 2. The mean value of different physiochemical parameters obtained for different tea types (values are given as mean \pm SD)

\begin{tabular}{lcc}
\hline Tea types & Total Polyphenol (mg PE/g sample)* & Antioxidant activity (\%)* \\
\hline CTC & $4.60 \pm 2.18^{\mathrm{b}}$ & $25.04 \pm 7.25^{\mathrm{c}}$ \\
Orthodox & $8.79 \pm 1.98^{\mathrm{b}}$ & $43.86 \pm 8.45^{\mathrm{b}}$ \\
Green & $18.20 \pm 3.42^{\mathrm{a}}$ & $72.39 \pm 6.69^{\mathrm{a}}$ \\
\hline
\end{tabular}

*Values with different superscripts on the same column are significantly different at $5 \%$ level of significance

Table 3. The mean value of different physiochemical parameters obtained for different commercial brands of tea (values are given as mean \pm SD)

\begin{tabular}{lcc}
\hline Tea commercial brands of tea & Total Polyphenol (mg PE/g sample)* & Antioxidant activity (\%) $^{*}$ \\
\hline CTC Tokla & $8.08 \pm 0.37^{\mathrm{e}}$ & $29.87 \pm 5.22^{\mathrm{e}}$ \\
CTC Mechi & $2.07 \pm 0.12^{\mathrm{g}}$ & $11.32 \pm 4.87^{\mathrm{f}}$ \\
CTC Welcome & $5.95 \pm 0.12^{\mathrm{f}}$ & $33.94 \pm 4.61^{\mathrm{de}}$ \\
Orth. Dhankute & $9.77 \pm 0.49^{\mathrm{d}}$ & $38.64 \pm 2.87^{\mathrm{d}}$ \\
Orth. Antuvalley & $7.77 \pm 0.00^{\mathrm{e}}$ & $32.43 \pm 1.74^{\mathrm{de}}$ \\
Orth. Kanchanjunga & $13.22 \pm 0.61^{\mathrm{c}}$ & $60.52 \pm 2.98^{\mathrm{c}}$ \\
Green Sencha & $15.78 \pm 0.74^{\mathrm{b}}$ & $61.12 \pm 1.82^{\mathrm{c}}$ \\
Green Kanchanjunga & $23.30 \pm 0.74^{\mathrm{a}}$ & $71.67 \pm 1.65^{\mathrm{b}}$ \\
Green Emerald & $24.62 \pm 0.37^{\mathrm{a}}$ & $84.38 \pm 3.12^{\mathrm{a}}$ \\
\hline
\end{tabular}

*Values with different superscripts on the same column are significantly different at $5 \%$ level of significance

The TPC of different tea types was also significant $(\mathrm{p}<0.05)$. The highest TPC was observed for green tea and that was significantly higher from both orthodox and CTC tea, whereas the average polyphenol content of CTC and orthodox tea was not significantly different.

Various literatures have also shown higher total polyphenol content in green tea than in black tea. Anesini et al., (2008) found the total polyphenol content higher in green tea $21.02 \pm 1.54$ to $14.32 \pm 0.45 \%$ of Gallic acid equivalents (GAE) and that of lower, $17.62 \pm 0.42$ to $8.42 \pm 0.55 \%$ of GAE in black tea. Yakozawa et al., (1998) and Atoui et al., (2005) also reported the amount of total polyphenols to be higher in green tea than in black tea. As stated by Gramza et al., (2005) the total polyphenol content of tea extracts varied from $245.8 \mathrm{mg} / \mathrm{g}$ to $837.6 \mathrm{mg} / \mathrm{g}$ catechin equivalents $(\mathrm{CE})(\mathrm{p}<0.001)$ and also depend on the kind of solvent used for the extraction. They also claimed that polyphenol content depend on origin and type of tea. Yao et al., (2006) found the polyphenol content of green tea, sold in Australian market $25 \%$ and that of black tea $18 \%$. But the total polyphenol content of green and black tea from variety Assamica was reported to be $30 \%$ and that from the variety Sinesis was 20\% (Harbowy and Balentine, 1997). However Quan et al., (2007) found the higher amount of total polyphenol content in green tea $(15.06 \pm 2.12 \mathrm{ppm} \mathrm{GE})$ than in

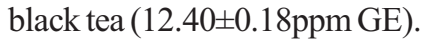

Chan et al., (2007) found the higher amount of polyphenols in young shoots of tea $(7666 \pm 488 \mathrm{mg} \mathrm{GAE} / 100 \mathrm{~g})$ and in young leaves $(7280 \pm 126 \mathrm{mg}$ GAE $/ 100 \mathrm{~g})$ than in mature tea leaves (5836 $\pm 294 \mathrm{mg} \mathrm{GAE} / 100 \mathrm{~g}$ ). Manzocco et al., (1998) also found the higher amount of total polyphenols in green tea $(94.5 \mathrm{mg} /$ g) than in black tea $(80.1 \mathrm{mg} / \mathrm{g})$. But Khokar and Magnusdottirr (2002) measured higher total polyphenol content in black tea $(80.5-134.9 \mathrm{mg} / 100 \mathrm{~g})$ than in green tea $(65.8-106.2 \mathrm{mg} / 100 \mathrm{~g})$. However the literatures were found to express the results of TPC as gallic acid equivalent or catechin equivalent. But the TPC obtained from the research were expressed as phenol equivalent and the exact correlation between gallic acid equivalent (and catechin equivalent) with phenol equivalent is not known. So the TPC obtained from the research and that as stated by the literatures may vary. Besides, the polyphenol content in tea is influenced by many factors such as tea types, commercial brands of tea, origin, tea plantation area; infusion conditions (Suteerapataranon et al., 2008). Highest levels are present in the bud and first leaf, and lowest levels in the internodes. Variations in the climate and agronomic practices can affect the composition of polyphenols, for e.g. the proportion of epigallocatechin-3-gallate is lower in plants grown in colder climates and also falls during cold season elsewhere. The proportion of different polyphenols may also vary due to shading and different application rates of nitrogenous fertilizers (Varnam and Sutherland, 1994). Besides the results showed that the unfermented tea such as green tea possessed higher level of polyphenols than that of fermented i.e. black tea. This may be due to conversion of natural tea polyphenols into thearubigins and theaflavin during the fermentation step in tea processing (Jain, 1999).

Antioxidant activity of different tea types and commercial brands of tea: The comparison of antioxidant activity of different tea types and commercial brands of tea were carried 


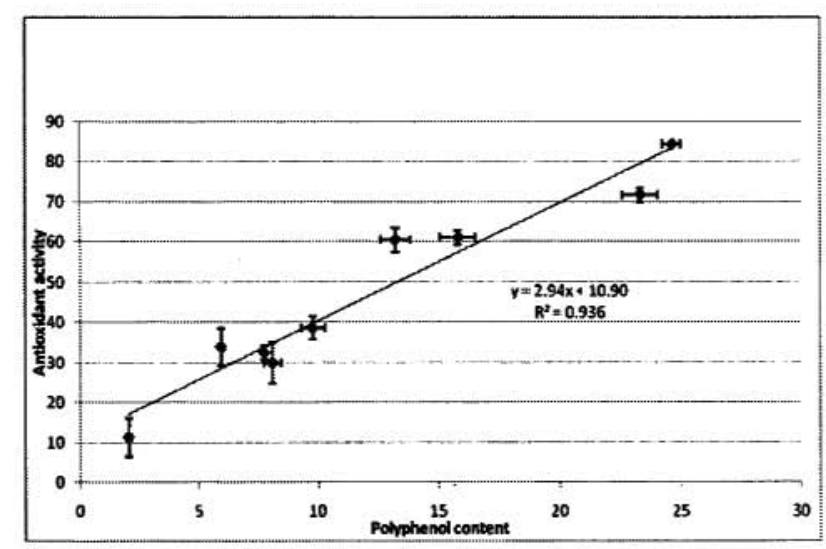

Figure 3. The total polyphenol content and antioxidant activity of different tea types (Error bar represents $95 \%$ confidence interval of mean)

out for the $0.36 \mathrm{mg}$ of tea samples. The average antioxidant activity of different tea types and commercial brands of tea for that particular concentration are shown in the Table 2 and 3 respectively. The average antioxidant activity of different tea types was significant $(p<0.05)$. The highest antioxidant activity was obtained for green tea and was significantly higher than both CTC and orthodox tea. Furthermore, the antioxidant activity of orthodox tea was significantly higher than that of CTC tea. This is also supported by various literatures (Yakozawa, 1998 and Lee et al., 2002). Moreover, effect of different tea commercial brands of tea were also found to have significant effect on antioxidant activity $(p<0.05)$. The highest antioxidant activity was observed for green tea Emerald and that was significantly higher than all other remaining commercial brands of tea.

Correlation between total polyphenol content and antioxidant activity: The correlation between total polyphenol content and antioxidant activity was studied. The total polyphenol content was found to be highly correlated with antioxidant activity $(\mathrm{r}=0.9678)$.

Anesini et al., (2008) also found good correlation between TPC and antioxidant activity with $\mathrm{r}=\mathbf{0 . 8 1 4 1}$ (based on DPPH free radical assay). This is also supported by Quan et al., (2007) as they also found good correlation between TPC and antioxidant activity $(\mathrm{r}=0.81)$. The regression analysis showed a linear relation between antioxidant activity and polyphenol content with high regression coefficient $\left(R^{2}=0.94\right)$ as shown in Figure 3. Green tea containing highest polyphenol content was found to show the highest antioxidant activity. This observation is in line with the different literatures clearly explaining the fact that polyphenolic compounds are mainly responsible for antioxidant activity of tea (Rice-Evans et al., 1996; Dufresne and Farnworth, 2001; Atoui et al., 2005). Different literatures have also described that green tea shows highest antioxidant activity than black tea (Yakozawa et al., 1998 and Lee et al., 2002).

\section{Conclusion}

From the research result, it can be concluded that the polyphenol content and antioxidant activity are vastly different among different tea types and commercial brands of tea. Among the tea types green tea had the highest amount of polyphenols than Orthodox tea and CTC tea. Green tea also showed the highest antioxidant activity among different tea types. Orthodox tea showed less antioxidant activity than that of green tea, but was significantly higher than that of CTC tea. Among the commercial brands of tea, green tea Emerald and Kanchanjunga were reported to have the highest polyphenol content and antioxidant activity. Furthermore, it can also be concluded that unfermented tea like Green tea contained the higher level of total polyphenols and antioxidant activity than that of fermented tea like CTC and Orthodox tea showing that fermentation step in the processing tea causes a decrease in the level of natural tea polyphenols and thus antioxidant activity. The antioxidant activity of tea was the best correlated with the total polyphenol content showing the polyphenols fractions of tea are responsible for the antioxidant activity.

\section{Acknowledgements}

The authors are grateful to Dr. Sitaram Joshi (NBSM-Nepal Bureau of Standards and Metrology) for providing the necessary chemicals, laboratory facilities, Mr. Shailesh Jha (NBSM), Mr. Ramesh Khadka (NBSM) and Mr. Krishna Sundar Shrestha as well for their enormous help.

\section{References}

Anesini C., Ferraro G. E. and Filip R. (2008). Total polyphenol and antioxidant capacity commercially available tea (Camellia sinesis) in Argentina. J. of Agri. and Food Chem., 56:9225-9229.

Anonymous (2009). Tea-coffee, Nepal Tea and Coffee development Board (NTDBC), pp 2, 9, 113.

Gramza A., Pawlak-Lemanska K., Korczak J., WasowiczE. and Rudzinska M. (2005). Tea extracts as free radical scavengers. J. Environmental Studies, 14: 861-867.

Hajimahmoodi M., Hanifeh M., Oveisi M. R., Sadeghi N. and Jannat B. (2008). Determination of total antioxidant capacity of green tea by ferric reducing/antioxidant power assay. Iranial J. Environment, Health Science and Engineering, 5(3): 167-172.

Harbowy M. E. and Balentine D. A. (1997). Tea chemistry, Crit. Rev. Plant Sci. 16: 415-480.

Jain N. K. (1999). Biosynthesis of precursors for liquor and flavor characteristics in black tea. In: Global Advances in Tea Science. Aravali books international (p) Ltd., New Delhi, pp 723-748. 
Joyce D. A. (1987). Oxygen radicals in disease. Adv. Drug Regulatory Bulletin, 127: 476-479.

Khokar S. and Magnusdottir S. G. M. (2002). Total phenol, catechin and caffeine contents of teas commonly consumed in United Kingdom. J. Agri. and Food Chem., 50: $565-570$.

Kinsella J. E., Frankel E., German B. and Kanner J. (1993). Possible mechanism for protective role of antioxidants in wine and plants. J. of Food Tech., 47: 85.

Larson R. A. (1998). The antioxidant of higher plants. Phytochemistry, 27: pp 969-978.

Lee K.W., Lee, H. J. and Lee C. Y. (2002). Antioxidant activity of black tea vs. green tea. J. of Nutr., 132:785.

Leung L. K., Su Y., Chen R., Zhang Z., Yu H. and Chen Z.Y. (2001). Theaflavins in black tea and catechins in green tea are equally effective antioxidants. J. of Nutr., 131: 2248-2251.

Manay N. S. and Shadaksharaswamy M. (2001). BeveragesTea. In: Food Facts and Principles. New age international publishers, India, pp 159-160.

Manzocco L., Anese M. and Nicoli M.C. (1998). Antioxidant properties of tea extracts as affected by processing. Lebensm-Wiss. U-technology, 31: 694-698.

Matsuzaki T. and Hara Y. (1985). Antioxidant activity of tea catechins. J. Agri. and Food Chem., 59(2):129-134.

Pan X., Niu G. and Liu H. (2003). Microwave assisted extraction of tea polyphenols and tea caffeine from green tea leaves. J. Food Sci., chemical Engineering and processing, 42:129.

Parr A. and Bowell G. P. (2000). Phenols in plant and in man: the potential for possible nutritional enhancement of the diet by modifying the phenols content or profile. J. Sci. Food and Agri., 80: 98-1012.

Percival M. (1998). Antioxidants. Clinical Nutrition Insights. 43:1-4.

Quan P. T., Hang T. V., Ha N. H. and Gang B. L. (2007). Total polyphenols, total catechins content and DPPH free radical scavenger activity of several types of Vietnam commercial green tea, J. Sci. and Tech. Develop., 10(10): 6-10.

Rice-Evans, Catherine A., Miller N. J. and Paganga G. (1996). Structure-antioxidant activity relationships of flavonoids and phenolics acids. Free Radical Biology and Medicine, 20(7): 933-956.

Shahidi F. (2000). Antioxidants in food and food antioxidants. Nahrung, 44: 159-163.
Siddhuraju P. and Becker K. (2003). Antioxidant properties of various solvent extracts of total phenolics constituents from three different agroclimatic origins of drumstick tree (Moringa oleifera Lam.) leaves. J. Agri. and Food Chem., 51:2144-2155.

Splus 8.0 for windows (Insight-ful Corp., Seatle, WA, USA), 2008 .

Suteerapataranon S. and Pudta D. (2008). Flow Injection Analysis-Spectrophotometry for Rapid Determination of Total Polyphenols in Tea Extracts. J. of Flow Injection Analysis, 25: 61-64.

Tea Research Association (2003). Tea chemistry. Available at: http://tocklai.net/TeaChem/index.aspx. [Accessed Jan, $16,2010]$

Varnam A. H. and Sutherland J. P. (1994). Tea, In: Beverage Technology, Chemistry and Microbiology". Chapman and Hall, London, pp 174-177.

Vinson J. A. and Dabbagh Y. A. (1998). Tea phenols: Antioxidant effectiveness of teas, tea components, tea fractions and their bindings with lipoproteins. Nutritional Research, 18:1067-1075.

Wang H. and Helliwell K. (2001). Determinaion of flavonols in green and black tea leaves and green tea infusions by hi-performance liquid chromatography. J. of Food Research Int., 34: 223-227.

Yakozawa T., Dong E., Nakagawa T., Kashiwagi H., Nakagawa H., Takeuchis S. and Chung H.Y. (1998). In vitro and in vivo studies on the radical scavenging activity of tea. $J$. Agri. and Food Chem., 46:2143-2150.

Yang C. S., Prabhu S. and Landau J. (2001). Prevention of carcinogenesis by tea polyphenols. J. Food Sci., 33(3 and 4):237-253.

Yao L. H., Jiang Y. M., Caffin N., D'arcy B., Datta N. and Liu X. (2006). Phenolics compounds in tea from Australian supermarkets. J. Food Chem., 96: 614-620.

Yen G. C. and Chen H. Y. (1995). Antioxidant activity of various tea extracts in relation to their anti-mutagenicity. J. Agri. and Food Chem., 43(2): 27-32.

Young I. S. and Woodside J. V. (2001). Antioxidants in health and disease. J. Clinical Pathology., 54: 176-186.

Zheng W. and Wang S.Y. (2001). Antioxidant activity and phenolics profile in selected herbs. J. Agri. and Food Chem., 49:5165-5170. 